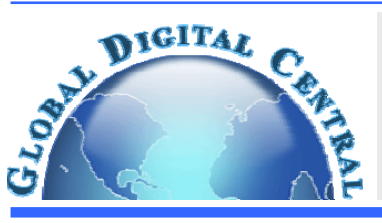

\title{
MAGNETOHYDRO DYNAMIC FLOW OF BLOOD IN A PERMEABLE INCLINED STRETCHING SURFACE WITH VISCOUS DISSIPATION, NON-UNIFORM HEAT SOURCE/SINK AND CHEMICAL REACTION
}

\author{
S.R.R. Reddy ${ }^{\mathrm{a}}$, P. Bala Anki Reddy ${ }^{\mathrm{a},{ }^{*}, \text { S. Suneetha }}{ }^{\mathrm{b}}$ \\ ${ }^{a}$ Department of Mathematics, School of Advanced Sciences, VIT University, Vellore-632014, INDIA. \\ ${ }^{b}$ Department of Applied Mathematics, Yogi Vemana University, Kadapa-516003, INDIA.
}

\section{ABSTRACT}

Present work aims to investigate the blood stream in a permeable vessel in the presence of an external magnetic field with heat and mass transfer. The instability in the coupled flow and temperature fields is considered to be produced due to the time-dependent extending velocity and the surface temperature of the vessel. The non-uniform heat source/sink effects on a chemically responded blood stream and heat viscous. This study is of potential value in the clinical healing of cardiovascular disorders accompanied by accelerated circulation. The problem is treated mathematically by reducing it to a system of joined non-linear differential equations, which have been solved by utilizing similarity transformation and boundary layer approximation. The resultant non-linear coupled ordinary differential equations are solved numerically by utilizing the fourth order Runge-Kutta method with shooting technique. Computational results are gotten for the velocity, temperature, the skin-friction coefficient, the rate of heat transfer and rate of mass transfer in the vessel. The evaluated results are compared with another analytical study reported earlier in scientific literatures. The present investigation exposes that the heat transfer rate is upgraded as the value of the unsteadiness parameter increases, but it decreases for the increment of the space reliance parameter for heat source/sink.
\end{abstract}

Keywords: MHD; permeability; viscous dissipation; non-uniform heat source/sink; chemical reaction.

\section{INTRODUCTION}

Fluid mechanics is a mesmerizing subject that it attracts the thought from both the scientists and general public. It is a science of materials which are in motion. If blood is considered as a fluid, then the equation of motion recommended by (Darcy, 1937, Brinkman, 1949) can be modified and can be used to know the mechanical properties and the flow characteristics of blood, in order to have a full understanding of the development of these diseases, which will help bioengineers who are engaged in the design and manufacture of improved artificial organs and finding solutions to some of the human body related diseases and disorders and also the development of pathological patterns in animal or human physiology.

Blood is a thick red liquid constantly. The fluid providing the body with nutrition, oxygen, and waste removal. Blood is a suspension of numerous cells - red blood cells (erythrocytes), white blood cells (leukocytes), and platelets in a liquid electrolyte solution called plasma. Plasma contains $90 \%$ of water and $7 \%$ of principal proteins (albumin, globulin, lipoprotein, and fibrinogen). Blood shows abnormal viscous properties, mainly due to the suspension of particles in plasma and it obeys the linear Newtonian model for viscosity (Cokelet, 1972). However, blood as a whole is considered as nonNewtonian fluid predominantly when the characteristic dimension of the flow is nearby the cell dimension. The two types of anomaly are due to low shear and high shear effects (Chien et al., 1984). Blood behaves like a Newtonian fluid (Bhatti et al., 2016, Ismail et al., 2007, Sinha et al., 2016). When blood flows through arteries with larger diameter at high shear rates.
Heat transfer through a fluid is significant in several thermal engineering applications, for instance, heat exchangers, refrigerators, automobiles and power plants. Numerous mathematical models have also been developed, which are applied to cryopreservation, cryosurgery and laser surgery. And also in many modern techniques of physiotherapy, which involve heating the affected portion of the human body. The therapeutic procedure of electromagnetic hyperthermia, in which the cancerous tissues are exposed to a thermal environment of $42^{\circ} \mathrm{C}$, while maintaining the neighbouring normal tissues at a suitable temperature, formulation and analysis of mathematical models on heat transfer through blood flow is very useful in the human circulatory system, blood flowing through different branches of the arteries or veins, heat is distributed through tissues evenly to the whole body and no heat is accumulated in any part of the tissue medium. The different mechanism for calculating the total quantity of heat carried by the blood when it flows through blood vessels include blood velocity, thickness of blood, vessel diameter, temperature of the adjoining tissues and heat transfer coefficient of blood. Barozzi and Dumas (1991) used a numerical method to study the convective heat transfer in blood vessels of the circulatory system. Many Researchers (Bhatti et al., 2018, Mahabaleshwar et al., 2017, Bhatti et al., 2017, Mabood et al., 2016, Bala Anki Reddy et al., 2016, Jai Qing et al., 2016, Bhatti et al., 2016, Abdul et al., 2016, Sharidan et al., 2006, Bhatti and Rashidi 2016) investigated the different flow problems over a stretching sheet with heat transfer. Chamka et al. (2010) analyzed similarity solution for unsteady heat and mass transfer from a stretching surface embedded in a porous medium.

Blood flow with radiation effect is one of the important subject of research, as it has got significant applications in Biomedical

\footnotetext{
*Corresponding author.Email: pbarmaths@gmail.com
} 
engineering and in numerous medical treatment methods, mainly in thermal therapeutic procedures. Infrared radiation is a technique of heat treatment which is done for various parts of the human body. This technique is chosen in heat therapy, as it is possible to directly heat the blood capillaries of the affected areas of the body. We use heat therapy in the treatment of muscle spasms, myalgia (muscle pain), chronic widespread pain and long-lasting shortening of muscle (medicinally called as contracture), bursitis, that is, inflammation of the fluid-filled sac (bursa) that lies between ligament and bone, or between ligament and skin and is observed to be more effective.

It is also used in the therapeutic procedure of hyperthermia, which has a well-recognized effect in oncology. The effect is attained by overheating the cancerous tissues (Szasz, 2007) by means of electromagnetic radiation. Misra et al. (2010) reported theoretical estimates of blood flow in arteries during the therapeutic procedure of electromagnetic hyperthermia used for treatment of cancer. A few important discussions are also available in that paper. A few investigations are reported by some researchers (Inoue et al., 1989, Nishimoto et al., 2006, Bidin and Nazar, 2009, Irfan et al., 2017, Ishak, 2011) to analyse the effects of electromagnetic radiation/ultrasonic radiation on blood flow. Misra and Sinha (2013) studied the MHD stream of blood and heat transfer in a permeable capillary in stretching movement with thermal radiation effect.

Generally, a viscous fluid normally sticks to a boundary, i.e., there is no slip of the fluid relative to the boundary. The no slip boundary state, which is the supposition that a liquid stick to a solid boundary, is one of the pillar of the Navier-Stokes theory. The non-adherence of the fluid to a solid boundary is called velocity slip. Velocity slip may arise on a stretching boundary when the fluid contains particulates such as emulsions, suspensions, foams and polymer solutions. Fluids exhibiting boundary slip also feature in diverse areas such as polishing of artificial heart valves and hydrophobic walls in fuel cells. Additionally, mass (solutal) slip can occur when simultaneous species diffusion occurs. Numerous studies have revealed the important influence of slip on nearwall flow characteristics. Misra et al. (1993) studied blood flow through a stenosed arterial segment, in view of no-slip condition at the vessel wall. But the usual no-slip condition at the boundary must be changed by the slip condition (Ebart and Sparrow, 1965). Some authors (Brunn, 1975, Nubar, 1971) suggested the existence of a red blood cell slip at the vessel wall. Misra and Kar (1989) developed a momentum integral method to study the problem of blood vessel in the present of a stenosis by taking into consideration the slip velocity at the wall. Several studies on slip effects and some other related problems were performed by some investigators (Hayat et al., 2011, Mukhopadhyay et al., 2012, Bala Anki Reddy and Suneetha, 2017).

In all the revisions declared above, viscous dissipation is neglected. But the viscous dissipation in the natural convective flow is important, when the flow field of extreme size or in high gravitational field. Such effects are important in geophysical flows and also in certain industrial geophysical flows operations and are usually characterized by the Eckert number. Gebhart (1962) examined that the effect of viscous dissipation may occur in natural convection in various devices which are subject to large decelerations or which operate at high rotational speeds. Viscous dissipation effects may also be present in stronger gravitational fields and in procedures wherein the scale of the process is very large, e.g., on larger planets, in large grassroots of gas in space, and in geological processes in fluids internal to various bodies. During the movement of fluid particles, viscosity of the fluid converts some kinetic energy into thermal energy. As this process is irreversible and caused due to viscosity, so this is called viscous dissipation. Initially the effect of viscous dissipation was considered by Brickman (1951). Chand et al. (2014) examined the problem of viscous dissipation and radiation on unsteady flow of electrically conducting fluid past over a stretching surface. The expressions of velocity and temperature were found with classical fourth order Runge-Kutta method.
The aim of the present investigation is to study the effect of chemical reaction, as well as heat and mass transfer on the MHD flow of blood over an inclined permeable stretching surface with an acute angle $\alpha$ to the vertical in the presence of a non-uniform heat source/sink. Thermal radiation, viscous dissipation, velocity slip, thermal slip and solutal slip conditions are taken into account. Because of the permeability of capillary blood vessel walls, consideration of the slip at the wall makes the study closer to the reality. The governing partial differential equations have been transformed into a system of ordinary differential equations by similarity transformations which are then solved numerically by using fourth order Runge-Kutta scheme together with the shooting method. The effects of various pertinent parameters on the momentum, heat and mass transfer characteristics have been studied and numerical results are presented graphically and in the tabular form. The results specify very clearly the threshold value of the magnitude of the magnetic field strength that should be applied to the human body. The study will be of profound interest to medical surgeons in regulating blood flow during surgery. These result shows that the characteristics of blood flow as well as the effects of heat and mass transfer in presence of chemical reaction that takes place during blood flow process due to the action of drugs. The numerical results for various parameters reported here are compared with the previously published works, for some special cases of the present study that are available in the literature. This paper has been arranged as follows: Section 2 deals with the mathematical formulation of the problem. Section 3 contains numerical results and discussions. The concluding remarks are presented in Sec. 4.

\section{MATHEMATICAL FORMULATION}

Let us consider an unsteady two-dimensional incompressible flow of blood over a permeable capillary inclined time-dependent stretching sheet with an acute angle $\alpha$ to the vertical. Blood is treated here as a viscous incompressible electrically conducting fluid. The coordinate system and flow model are shown in Figure 1.

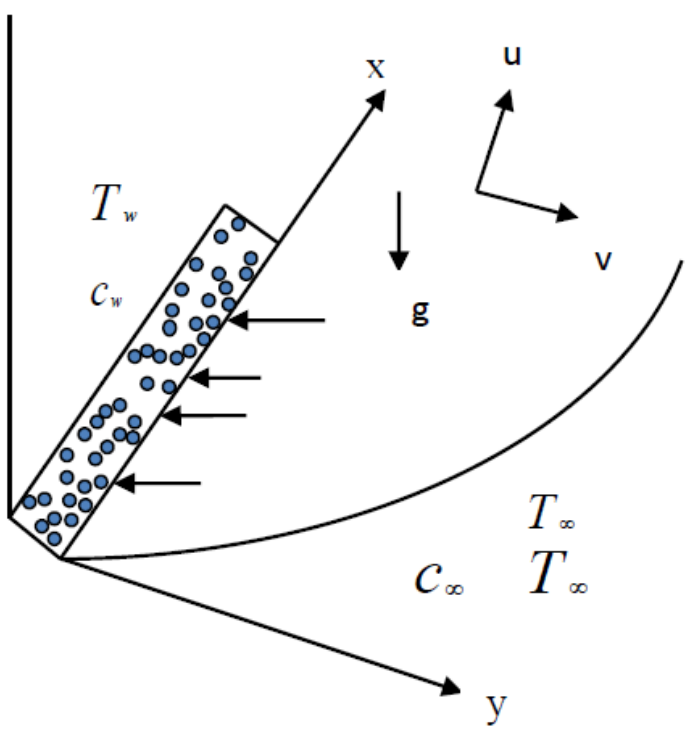

Fig. 1 Physical sketch of the problem.

At time $\mathrm{t}=0$, the sheet is impulsively stretched with velocity $U_{w}(x, t)=\frac{a x}{(1-c t)}$ along the $\mathrm{x}$-axis, where the origin is kept fixed in the fluid medium of ambient temperature $T_{\infty}$. A magnetic field $B(t)$ is applied perpendicular to the sheet, with an acute angle $\xi$. This magnetic field acts like transverse magnetic field at $\xi=\frac{\pi}{2}$. It is assumed that the 
magnetic Reynolds number is much less than unity so that the induced magnetic field is negligible in comparison to the applied magnetic field. The velocity slip, thermal slip, solutal slip and first-order homogeneous time-dependent chemical reaction have been taken into account. The fluid properties are assumed to be constant. Under these assumptions and following Chamka et al (2010) and Misra and Sinha (2013)), the governing equation of the boundary layer that are based on the balance laws of mass, linear motion, energy and concentration species for the blood flow in the presence of thermal radiation take the following form:

$\frac{\partial u}{\partial x}+\frac{\partial v}{\partial y}=0$,

$\frac{\partial u}{\partial t}+u \frac{\partial u}{\partial x}+v \frac{\partial u}{\partial y}=v \frac{\partial^{2} u}{\partial y^{2}}+g \beta\left(T-T_{\infty}\right) \cos \alpha+$

$$
g \beta^{*}\left(C-C_{\infty}\right) \cos \alpha-\frac{\sigma B^{2}(t)}{\rho} \sin ^{2} \xi u-\frac{v}{k_{1}(t)} u,
$$

$\frac{\partial T}{\partial t}+u \frac{\partial T}{\partial x}+v \frac{\partial T}{\partial y}=\frac{k}{\rho C_{p}} \frac{\partial^{2} T}{\partial y^{2}}-\frac{1}{\rho C_{p}} \frac{\partial q_{r}}{\partial y}+\frac{q^{\prime \prime \prime}}{\rho C_{p}}+\frac{v}{C p}\left(\frac{\partial u}{\partial y}\right)^{2}$,

$\frac{\partial C}{\partial t}+u \frac{\partial C}{\partial x}+v \frac{\partial C}{\partial y}=D \frac{\partial^{2} C}{\partial y^{2}}-\Gamma(t)\left(C-C_{\infty}\right)$.

Subject to the boundary conditions:

$u=U_{w}+N \mu \frac{\partial u}{\partial y}, v=V_{w}, T=T_{w}+K \frac{\partial T}{\partial y}, C=C_{w} P \frac{\partial c}{\partial y}$ at $y=0$

$u \rightarrow 0, T \rightarrow T_{\infty}, C \rightarrow C_{\infty}$ as $y \rightarrow \infty$.

Where $V_{w}$ represents the injection/suction velocity given by

$V_{w}=-\sqrt{\frac{v U_{w}}{x}} f(0)$.

Equation (6) indicates that the mass transfer at the surface of the capillary wall takes place with a velocity $V_{w}$ where $V_{w}>0$ in the case of injection and $V_{w}<0$ in the case of suction. In Eq. (2), $k_{1}(t)=k_{2}(1-c t) \quad$ represents the time-dependent permeability parameter, in Eq. (5), $N=N_{0}(1-c t)^{\frac{1}{2}}$ is the velocity slip factor. $K=K_{0}(1-c t)^{\frac{1}{2}}$ is the thermal slip factor and $P=P_{0}(1-c t)^{\frac{1}{2}}$ is the concentration slip factor. The no-slip conditions can be recovered, by putting $N=K=P=0$. The velocity $U_{w}(x, t)$ of the stretching motion of the blood vessel, surface temperature $T_{w}(x, t)$ and the concentration $C_{w}(x, t)$ are considered as

$U_{w}=\frac{a x}{1-c t}, T_{w}=T_{\infty}+\frac{b x}{1-c t}, C_{w}=C_{\infty}+\frac{d x}{1-c t}$.

where a, b, c and $d$ are the constants such that $a>0, b \geq 0, c \geq 0, d \geq 0$ and $c t<1$. Let us consider $B(t)=B_{0}(1-c t)^{-\frac{1}{2}}$ and $\Gamma(\mathrm{t})=\Gamma_{0}(1-c t)^{-1}$, where $\mathrm{B}_{0}$ is a constant representing the magnetic field strength at $t=0, \Gamma_{0}$ is a constant, $u$ and $v$ are the velocity components in the $x$ and $y$ directions, respectively, $g$ is the acceleration due to gravity, $\rho$ is the density of the fluid, $\beta$ is the coefficient of thermal expansion, $\beta^{*}$ is the coefficient of expansion with concentration, $T$ is the temperature, $T_{\infty}$ is the temperature of the ambient fluid, $C$ is the concentration, $C_{\infty}$ is the concentration of the ambient fluid, $\sigma$ is the electrical conductivity, $v$ is the kinematic viscosity, $k$ is the thermal conductivity, $C_{p}$ is the specific heat at constant pressure, $q_{r}$ is the radiative heat flux and $\mathrm{D}$ is the mass diffusion coefficient. The non-uniform heat source/sink, $q$ " is modeled as

$q^{\prime \prime \prime}=\frac{K U_{w}(x, t)}{x v}\left[A *\left(T_{w}-T_{\infty}\right) f^{\prime}+B *\left(T-T_{\infty}\right)\right]$.

Where $\mathrm{A}^{*}$ and $\mathrm{B}^{*}$ are the coefficient of space and temperature dependent heat source/sink, respectively. It is to be noted that the case $A^{*}>0, B^{*}>0$ corresponds to internal heat generation and that $A^{*}<0, B^{*}<0$, corresponds to internal heat absorption.

Thermal radiation is simulated using the Rosseland diffusion approximation and in accordance with this, the radiative heat flux $q_{r}$ is given by

$q_{r}=-\frac{4 \sigma^{*}}{3 k^{*}} \frac{\partial T^{4}}{\partial y}$.

Where $k^{*}$ is the Rosseland mean absorption coefficient and $\sigma *$ is the Stefan-Boltzman constant. If the temperature differences within the mass of blood flow are sufficiently small, then Eq. (8) can be linearized by expanding $T^{4}$ into the Taylor's series about $T_{\infty}$, and neglecting higher-order terms, we get

$T^{4} \cong 4 T_{\infty}^{3} T-3 T_{\infty}^{4}$.

We introduce the self-similar transformations (see Chamka et al (2010), Srinivas et al. (2014) and Misra and Sinha (2013)

$\eta=\left(\frac{U_{w}}{v_{x}}\right)^{\frac{1}{2}} y, \psi=\left(v_{x} U_{w}\right) \frac{1}{2} f(\eta)$,
$\theta(\eta)=\frac{T-T_{\infty}}{T_{w}-T_{\infty}}, \phi(\eta)=\frac{C-C_{\infty}}{C_{w}-C_{\infty}}$.

Where $\eta$ is the similarity variable and $\psi$ is the stream function. The velocity components are $u=\frac{\partial \psi}{\partial y}, v=-\frac{\partial \psi}{\partial x}$, which identically satisfies Eq. (1). Now substituting (9) and (10) into the Eqs. (2)-(4), we get the following set of ordinary differential equation

$$
\begin{gathered}
f^{\prime \prime \prime}+f f^{\prime \prime}-\left(f^{\prime}\right)^{2}-A\left(f^{\prime}+\frac{1}{2} \eta f^{\prime \prime}\right)+G r \theta \cos \alpha \\
+G c \phi \cos \alpha-M \sin ^{2} \xi f^{\prime}-\frac{1}{K_{3}} f^{\prime}=0, \\
\frac{(1+R)}{p_{r}} \theta^{\prime \prime}+f \theta^{\prime}-f^{\prime} \theta-A\left(\theta+\frac{1}{2} \eta \theta^{\prime}\right) \\
+\frac{\left(A^{*} f^{\prime}+B^{*} \theta\right)}{p_{r}}+E c\left(f^{\prime}\right)^{2}=0, \\
\frac{1}{S c} \phi^{\prime \prime}+f \phi^{\prime}-f^{\prime} \phi-A\left(\phi+\frac{1}{2} \eta \phi^{\prime}\right)-\gamma \phi=0 .
\end{gathered}
$$

where $A ; M ; k_{3} ; G r ; G c ; R ; P r ; S c$ and $\gamma$ are non-dimensional parameters called, respectively, the unsteadiness parameter, Hartmann number, permeability parameter, Grashof number, solutal Grashof number, radiation parameter, Prandtl number, Schmidt number and chemical reaction parameter are given by

$$
\begin{aligned}
& A=\frac{c}{a}, \quad M=B_{0} \sqrt{\frac{\sigma}{\rho a}}, K_{3}=\frac{a k_{2}}{v}, \quad G r=\frac{g \beta x\left(T_{w}-T_{\infty}\right)}{U_{w}^{2}}, \\
& E c=\frac{U_{w}^{2}}{C p\left(T_{w}-T_{\infty}\right)}, G c=\frac{g \beta^{*} x\left(c_{w}-c_{\infty}\right)}{U_{w}^{2}}, R=\frac{16 \sigma^{*} T_{\infty}^{3}}{3 k k^{*}},
\end{aligned}
$$


$\operatorname{Pr}=\frac{\mu c p}{k}, S c=\frac{v}{D}$ and $\gamma=\frac{\Gamma_{0}}{a}$.

The corresponding boundary conditions are

$f=S, \quad f^{\prime}=1+S_{f} f^{\prime \prime}(0), \theta=1+S_{t} \theta^{\prime}(0)$,

$$
\phi=1+S_{c} \phi^{\prime}(0) \text { at } \eta=0
$$

$f^{\prime} \rightarrow 0, \theta \rightarrow 0, \phi \rightarrow 0, \phi \rightarrow 0, \eta \rightarrow \infty$.

In Eq. (15), $S<0$ and $S>0$ correspond to injection and suction, respectively. The non-dimensional velocity slip $\mathrm{S}_{\mathrm{f}}$, thermal slip $\mathrm{S}_{\mathrm{t}}$ and solutal slip $\mathrm{S}_{\mathrm{c}}$ are defined by

$$
S_{f}=N_{0} \rho \sqrt{a v}, S_{t}=K_{0} \sqrt{\frac{a}{v}} \text { and } S_{c}=P_{0} \sqrt{\frac{a}{v}} \text {. }
$$

Where the prime denotes derivatives with respect to $\eta$. It may be noted that when $\mathrm{A}=0$ in Eqs. (11)-(13), the problem will be reduced to the one in the steady state. Also, the quantities of physical interest in this problem are the skin friction coefficient, heat transfer rate and mass transfer which are defined as

$$
C_{f}=\frac{\tau_{w}}{\frac{\rho U_{w}^{2}}{2}}, N u_{x}=\frac{x q_{w}}{k\left(T_{w}-T_{\infty}\right)}, S h_{x}=\frac{m_{w} x}{\rho D\left(c_{w}-c_{\infty}\right)} .
$$

Where the wall shear stress, surface heat flux and the mass flux are given by

$$
\begin{aligned}
& \tau_{w}=\mu\left(\frac{\partial u}{\partial y}\right)_{y=0}, q_{w}=-k\left(\frac{\partial T}{\partial y}\right)_{y=0}, \\
& m_{w}=-\rho D\left(\frac{\partial c}{\partial y}\right)_{y=0} .
\end{aligned}
$$

Using Eq. (17), quantity (16) can be expressed as

$$
C_{f}=\frac{1}{2} \operatorname{Re}_{x}^{-\frac{1}{2}} f^{\prime \prime}(0), N u_{x}=-\operatorname{Re}_{x}^{-\frac{1}{2}} \theta^{\prime}(0), \quad S h_{x}=-\operatorname{Re}_{x}^{-\frac{1}{2}} \phi^{\prime}(0) .
$$

The above skin-friction coefficient, local Nusselt number and Sherwood number show that their variations depend on the variation of the factors $f^{\prime \prime}(0),-\theta^{\prime}(0)$ and $-\phi^{\prime}(0)$ respectively.

\section{RESULTS AND DISCUSSIONS}

For numerical results, we considered $G r=2.0, G c=2.0, K_{3}=0.4$, $\xi=\pi / 4, \alpha=\pi / 4, M=1.0, S=0.5, \mathrm{~S}_{f}=1.5, \mathrm{~S}_{t}=1.0, \mathrm{~S}_{c}=0.5, p r=21$, $\mathrm{R}=0.5, A^{*}=0.5, B^{*}=0.5, E c=0.5, Q=0.5, S c=0.6, \gamma=0.5$. These

values are conserved as common unless specifically pointed out in the appropriate graphs.

Figures 2-9 depict the influence of non-dimensional axial velocity for different values of Hartmann number, permeability parameter, thermal Grashof number, solutal Grashof number, velocity slip factor, suction parameter, inclination respectively. Figure 2 shows that the axial velocity lowers as Hartmann number increases. This is due to the fact that an increase in Hartmann number signifies an enhancement of Lorentz force, thus reducing the magnitude of the velocity. This reveals an important observation that the motion of the blood in a carrying blood vessel can be regulated by applying a magnetic field externally and varying the intensity of the applied field. Figure 3 displays the variations of velocity profile with changes in the permeability parameter. From this figure it can be observed that an increase in the permeability enhances the velocity of the blood. One can see that, for small permeability $\left(K_{3}=0.1\right)$, the axial velocity reduces faster than the case when the permeability is higher $\left(\mathrm{K}_{3}=0.3\right.$; $0.5)$. The variation of the axial velocity for both thermal Grashof number $(G r)$ and solutal Grashof number $(G c)$ for steady and unsteady flows are shown in Figures 4 and 5. Gr signifies the relative effect of the thermal resistance force to the viscous hydrodynamic force in the boundary layer regime. An increase in $G r$ induces a rise in the steady and unsteady state velocity profiles. There is a rapid rise in the velocity near the wall and then the velocity descends smoothly towards zero. Figure 6 presents the velocity profiles for various values of velocity-slip factor. With the increasing values of velocity slip parameter, the blood velocity reduces. When slip occurs, the blood flow velocity near the blood vessel is no longer identical to the sheet stretching velocity, i.e., a velocity slip exists. With the rise in $\mathrm{S}_{\mathrm{f}}$ such a slip velocity increases.

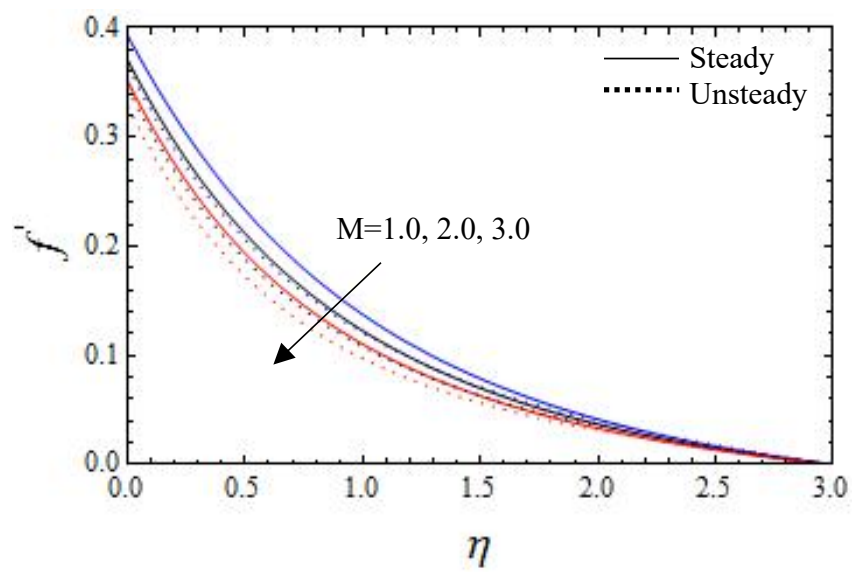

Fig. 2 Velocity profiles for different values of $\mathrm{M}$

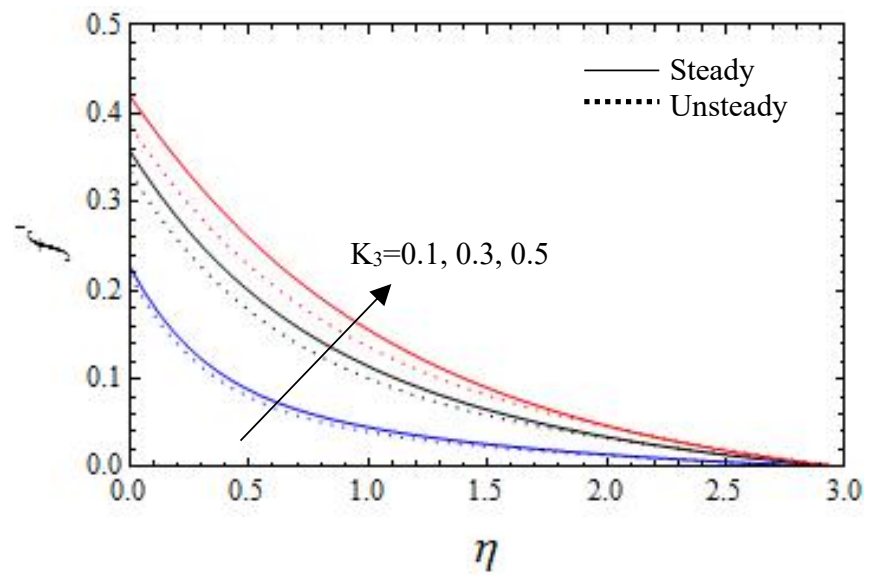

Fig. 3 Velocity profiles for different values of $\mathrm{K}_{3}$

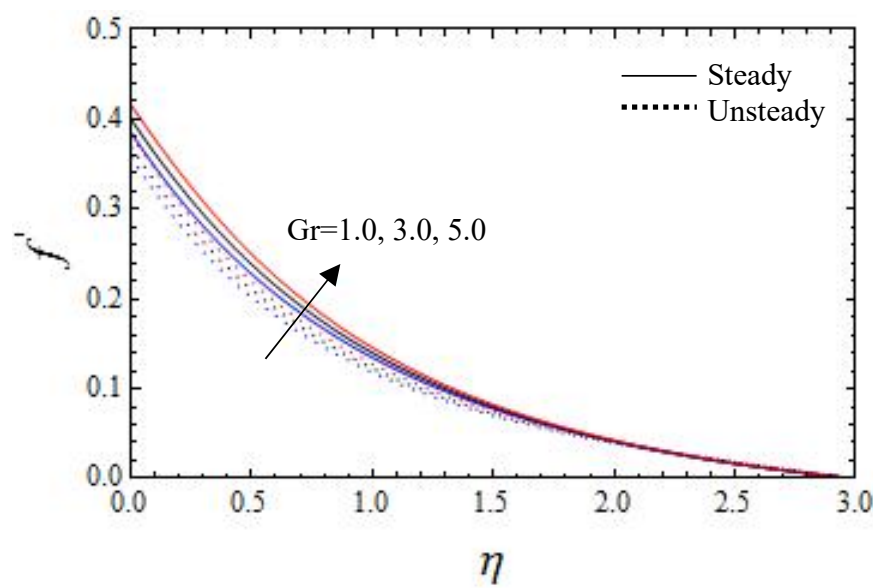

Fig. 4 Velocity profiles for different values of $\mathrm{Gr}$ 


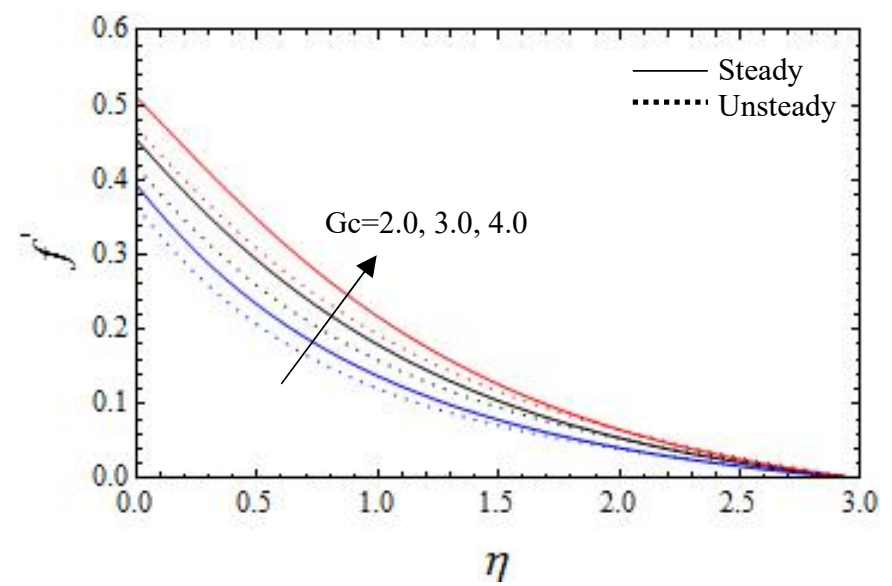

Fig. 5 Velocity profiles for different values of Gc

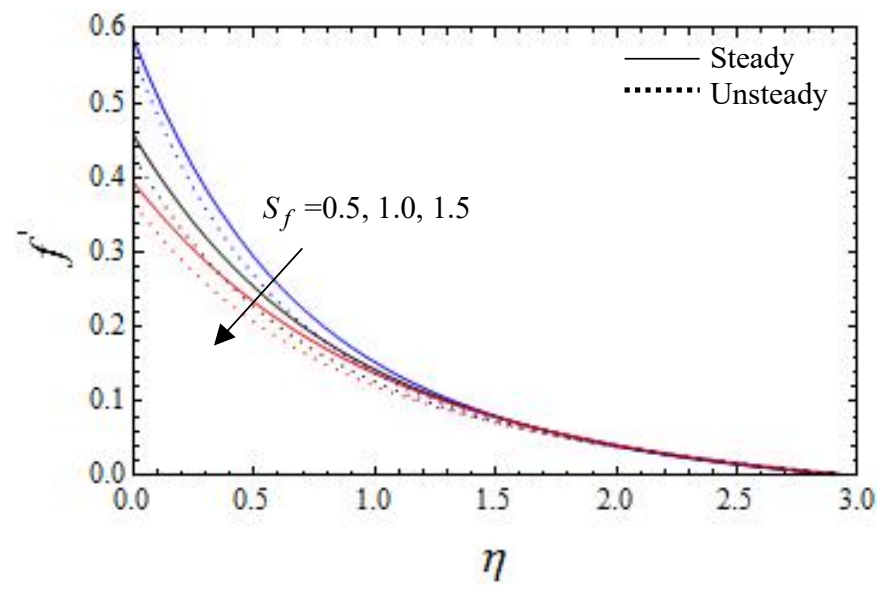

Fig. 6 Velocity profiles for different values of $S_{f}$

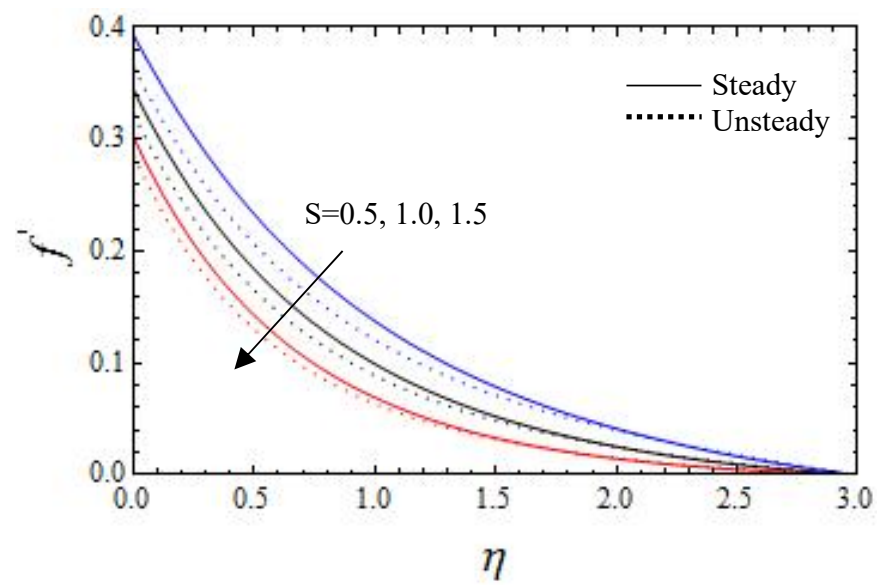

Fig. 7 Velocity profiles for different values of S

Figure 7 is aimed to shed light on the effect of suction parameter on the velocity distribution in the boundary layer. It reveals that the velocity profiles slightly decrease with an increase in the suction parameter. This is because the heated fluid is pushed towards the wall where the buoyancy forces can act to retard the fluid due to high influence of viscosity. From Figure 8 we can infer that the velocity profiles decrease with an increase in the inclination parameter. This can be certified to the fact that the angle of inclination decreases the effect of the buoyancy force due to thermal diffusion by a factor of $\cos \alpha$. Consequently, the driving force to the fluid decreases as a result

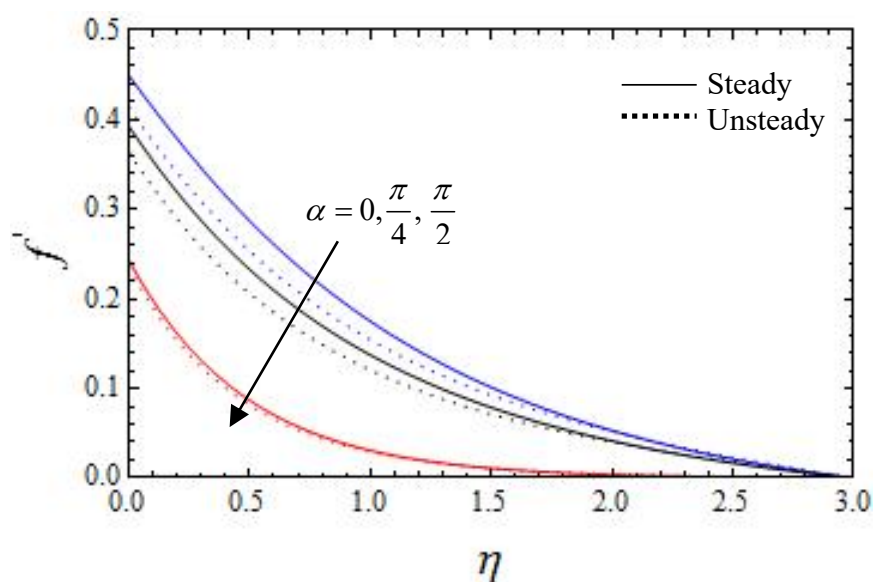

Fig. 8 Velocity profiles for different values of $\alpha$

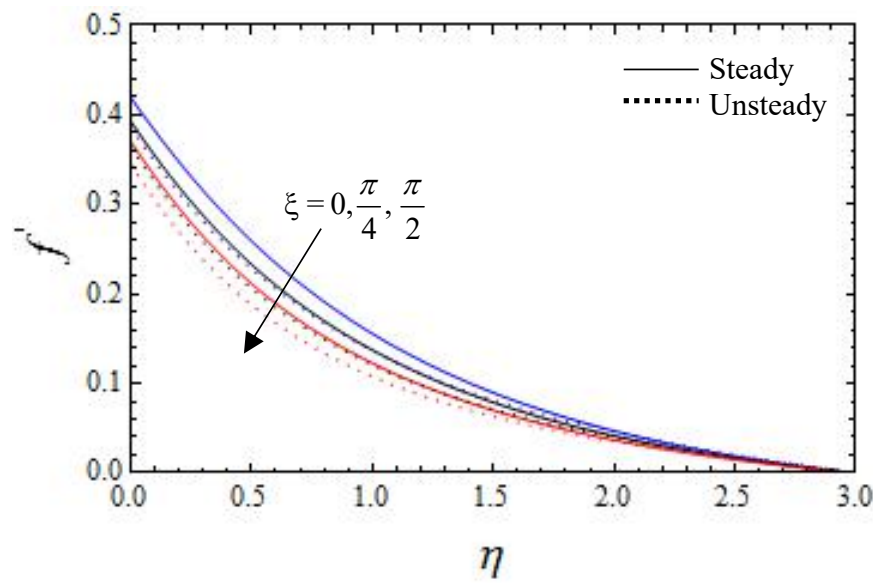

Fig. 9 Velocity profiles for different values of $\xi$

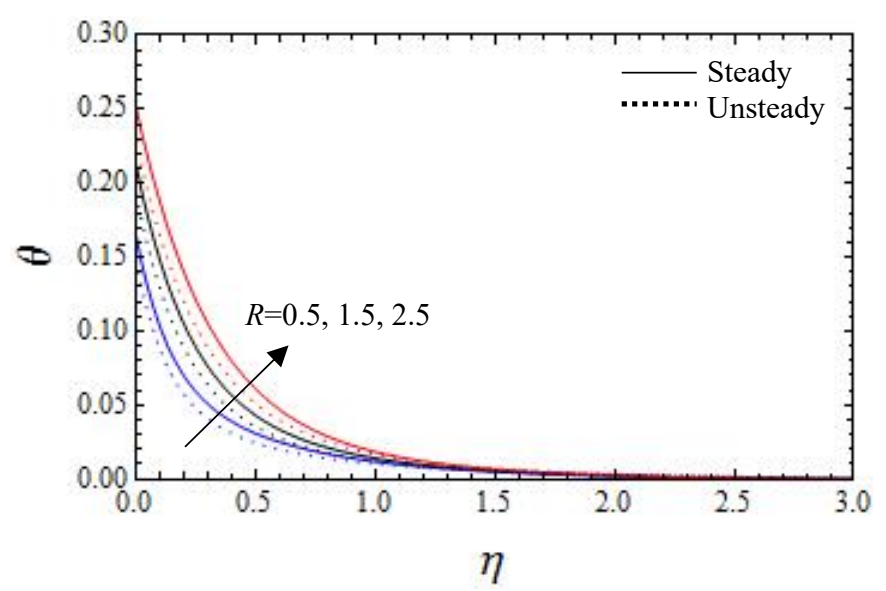

Fig. 10 Temperature profiles for different values of $R$

velocity of the fluid decreases. Figure 9 displays the velocity profile for various values of aligned angle $\xi$. The velocity profile of the fluid decreases with increasing the aligned angle. The reason for this is increase in the aligned angle causes to strengthen the magnetic field. Due to this enhanced magnetic field, it generates opposite force to the flow, this force is called Lorentz force. Figures 10-16 focus on the temperature distribution for various values of thermal radiation parameter, Prandtl number, unsteadiness parameter, temperature dependent source/sink, Eckert number, thermal slip parameter and inclination. The temperature profiles are presented for several values 


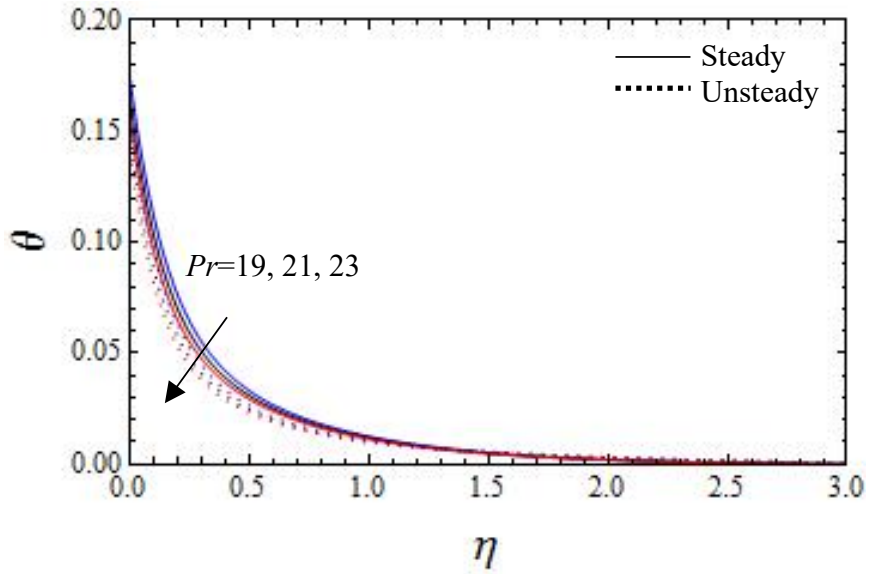

Fig. 11 Temperature profiles for different values of $\operatorname{Pr}$

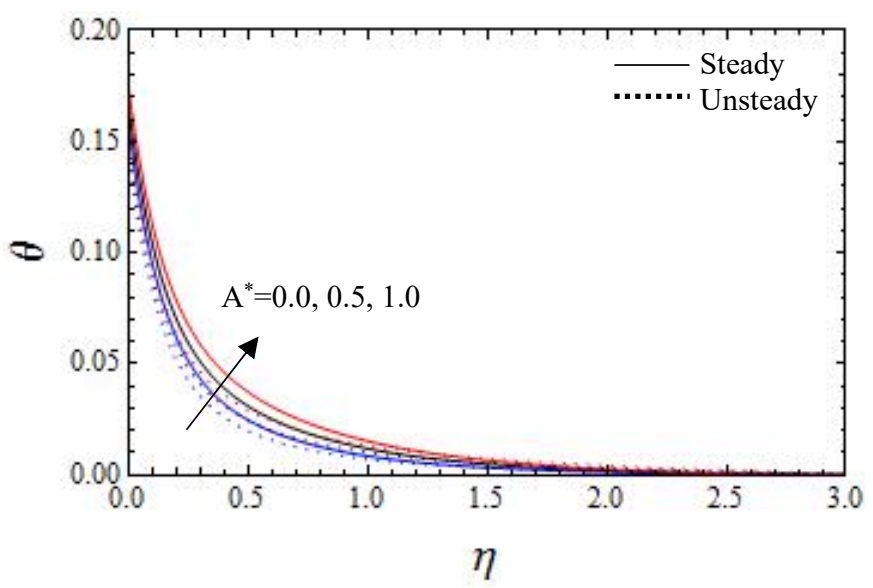

Fig. 12 Temperature profiles for different values of $A^{*}$

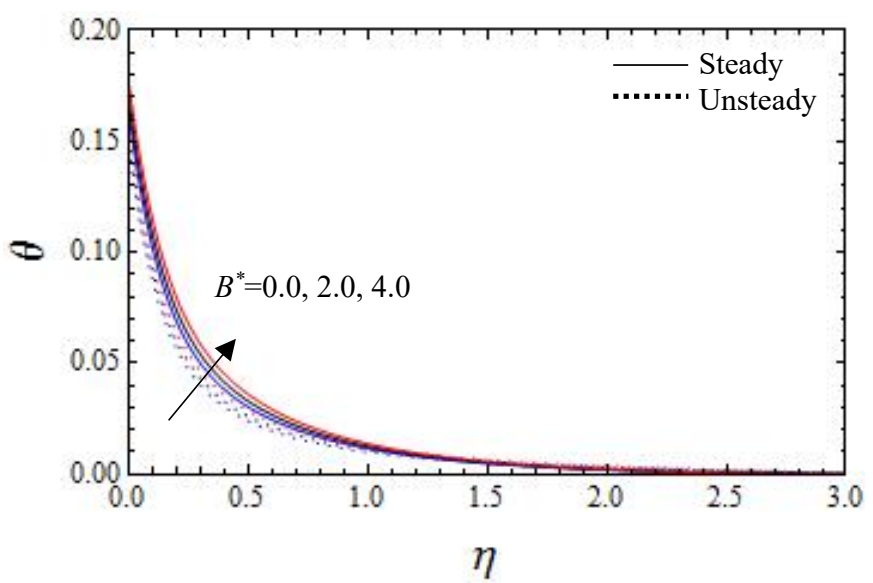

Fig. 13 Temperature profiles for different values of $B^{*}$

of thermal radiation parameter in Figure 10. It is found that the temperature enhances as the radiation increases. This may be attributed to the physical fact that the thermal boundary layer thickness enhances with increasing radiation parameter. Figure 11 demonstrates the effect of Prandtl number on the temperature distribution. The numerical results show that the increase in the Prandtl number results in a decrease of the thermal boundary layer thickness and in general lesser average temperature with in the boundary layer. The reason is that smaller values of $\operatorname{Pr}$ are equal to

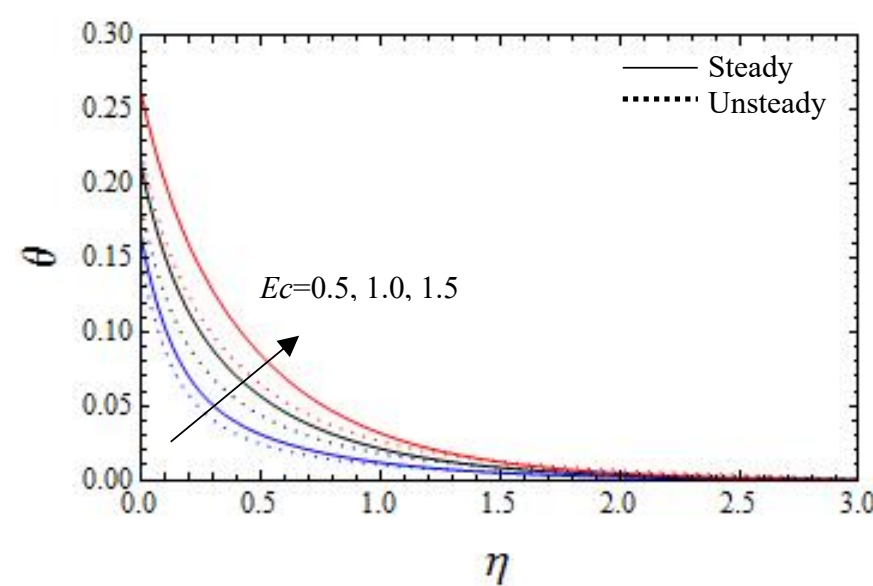

Fig. 14 Temperature profiles for different values of $E c$

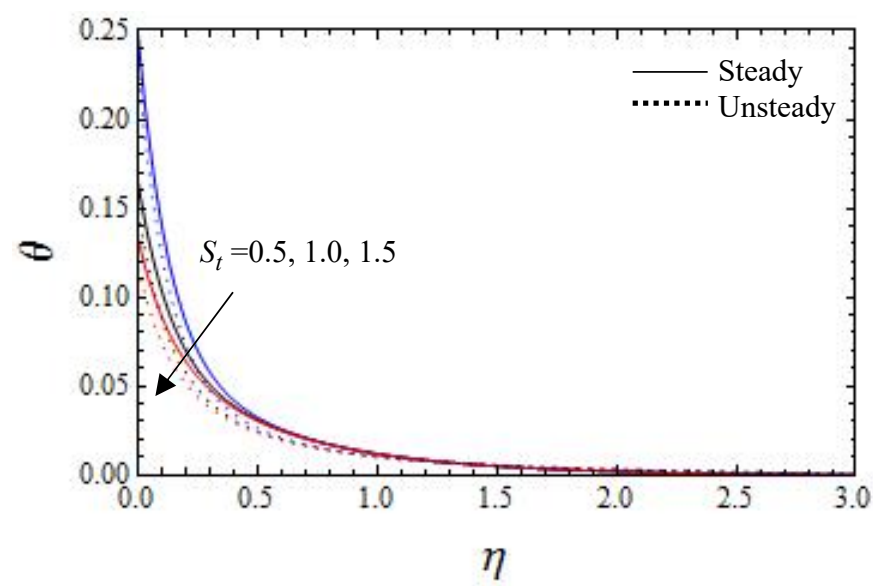

Fig. 15 Temperature profiles for different values of $S_{t}$

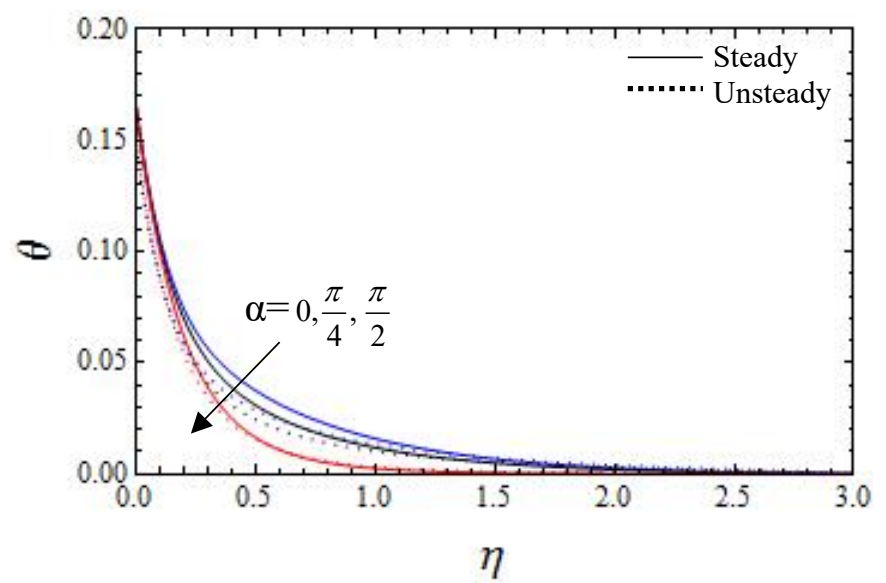

Fig. 16 Temperature profiles for different values of $\alpha$

increasing the thermal conductivity of the fluid, and therefore heat is able to diffuse away from the heated surface faster than higher values of $P r$. Hence in the case of smaller $P r$, the thermal boundary layer is denser and the rate of heat transfer is reduced. Therefore, an increase in $\mathrm{Pr}$ reduces temperature. Figure 12 represents the temperature profiles for various values of unsteadiness parameter. It is observed from this figure that as the unsteadiness parameter increases, the temperature of the boundary layer diminishes. The variations in the temperature profiles for changes in the heat source/sink are presented 


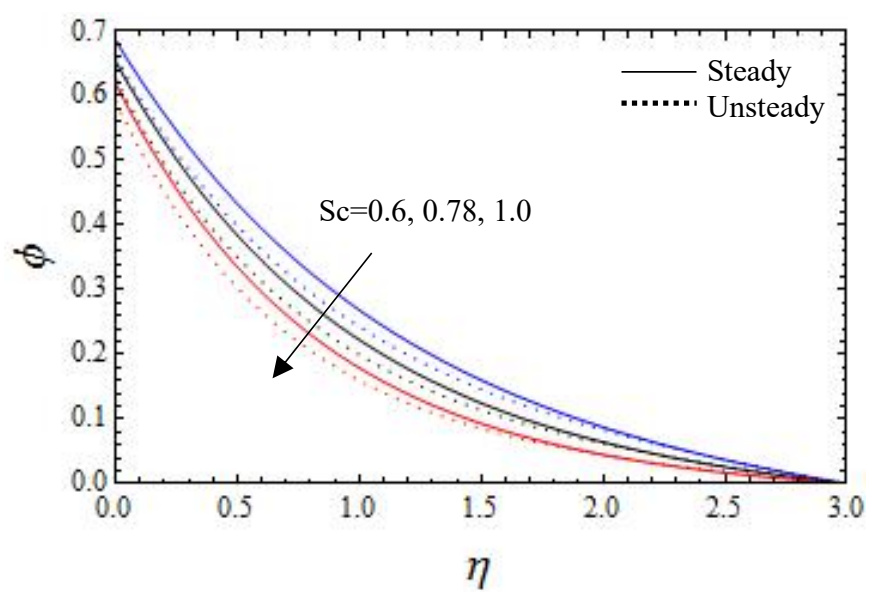

Fig. 17 Concentration profiles for different values of Sc

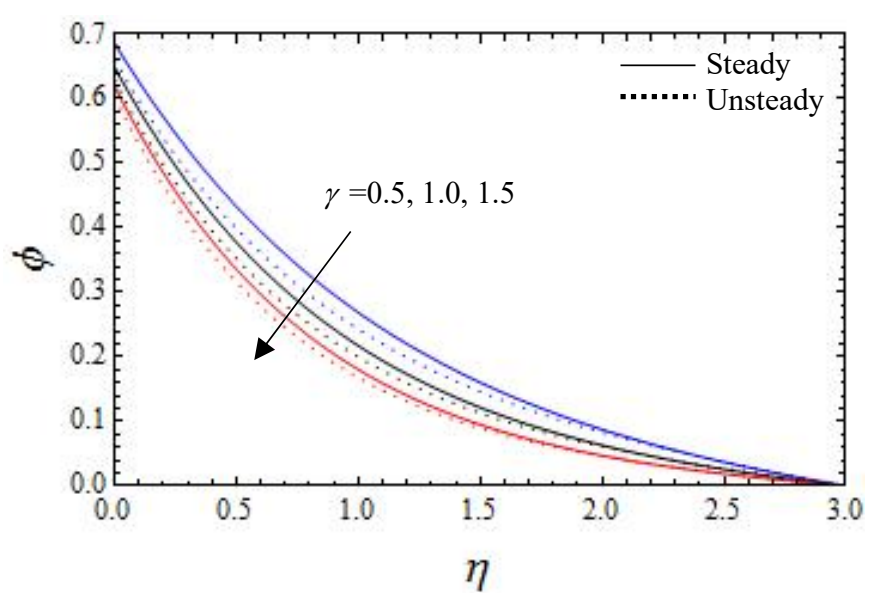

Fig. 18 Concentration profiles for different values of $\gamma$

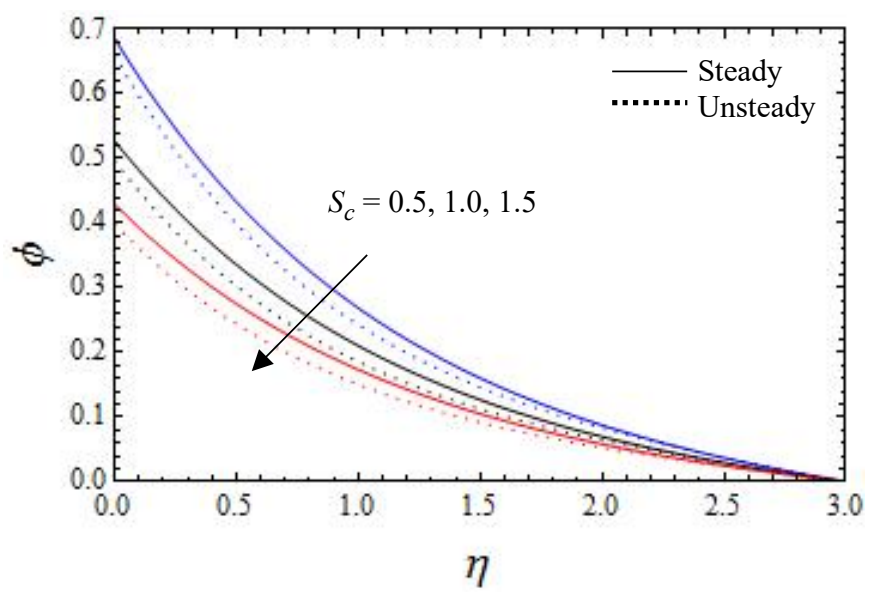

Fig. 19 Concentration profiles for different values of $S_{c}$

in Figure 13. It is observed that the temperature enhances with an increase in heat source. The effect of Eckert number $E c$, on temperature is shown in Figure 14. Number $E c$, designates the ratio of the kinetic energy of the flow to the boundary layer enthalpy difference. As Ec is enhanced, the temperature increases, since internal energy is increased. Temperature profiles for the various values of thermal slip parameter are shown in Figure 15. It is seen from this figure that the thermal slip parameter increases, less heat is transferred from the stretched vessel to the fluid and hence the temperature decreases. Effects of inclination parameter on the temperature profiles are shown in Figure16. It is noticed that the thermal boundary layer thickness decreases by increasing the angle of inclination.

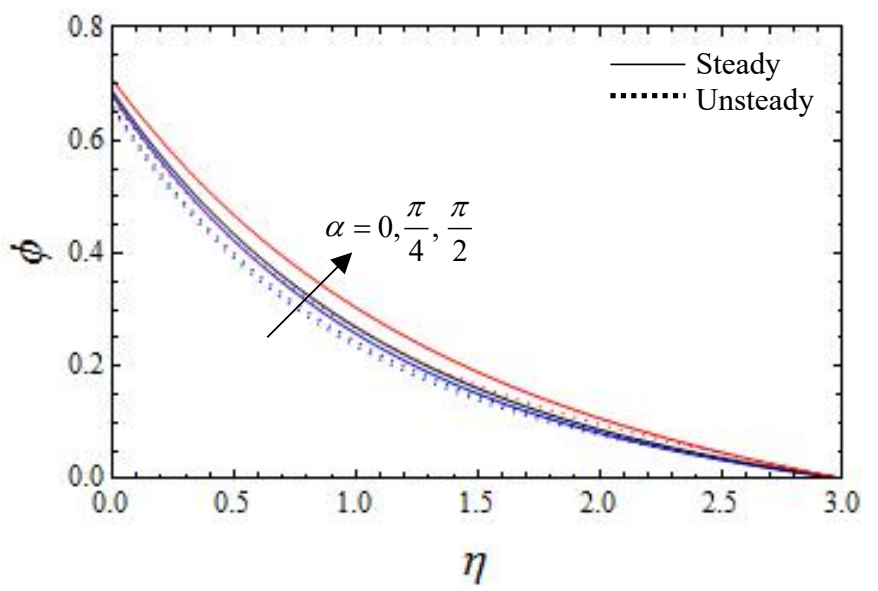

Fig. 20 Concentration profiles for different values of $\alpha$

Table 1 Comparison of results of skin friction coefficient for several values of unsteadiness parameter in the absence of Hartmann number, permeability parameter, Grashof number, modified Grashof number, coefficients of space and temperature dependent heat source/sink, Schmidt number and slip conditions.

\begin{tabular}{|c|c|c|c|}
\hline $\mathbf{A}^{*}$ & $\begin{array}{l}\text { Sharidan et al. } \\
(2006) \\
f^{\prime \prime}(0)\end{array}$ & $\begin{array}{lll}\text { Chamka } & \text { et } & \text { al. } \\
(2010) & & \\
-f^{\prime \prime}(0) & & \end{array}$ & $\begin{array}{c}\text { Present } \\
f^{\prime \prime}(0)\end{array}$ \\
\hline 0.8 & -1.26104 & 1.26151 & -1.26108 \\
\hline 1.2 & -1.37772 & 1.37805 & -1.37777 \\
\hline 2.0 & -1.58736 & & -1.58741 \\
\hline
\end{tabular}

Table 2 Comparison of results of the wall temperature gradient $-\theta^{\prime}(0)$ for several values of unsteadiness parameter, suction and the Prandtl number in the absence of angle of inclination, Hartmann number, permeability parameter, Grashof number, modified Grashof number, thermal radiation, Schmidt number and slip conditions.

\begin{tabular}{|c|c|c|c|c|c|c|}
\hline $\mathbf{A}^{*}$ & $\mathbf{S}$ & Pr & $\begin{array}{l}\text { Gurbka } \\
\text { and } \\
\text { Bobba } \\
(1985)\end{array}$ & $\begin{array}{l}\text { Ishak } \\
\text { et al. } \\
(2011)\end{array}$ & $\begin{array}{l}\text { Hayat et } \\
\text { al. } \\
(2011)\end{array}$ & Present \\
\hline \multirow[t]{12}{*}{0} & -1.5 & 0.72 & & 0.4570 & 0.45702 & 0.45702 \\
\hline & & 1.0 & & 0.5000 & 0.50000 & 0.500005 \\
\hline & & 10.0 & & 0.6452 & 0.64516 & 0.64516 \\
\hline & 0 & 0.01 & 0.0197 & 0.0197 & & 0.01970 \\
\hline & & 0.72 & 0.8086 & 0.8086 & 0.80863 & 0.80863 \\
\hline & & 1.0 & 1.0000 & 1.0000 & 1.00000 & 1.00000 \\
\hline & & 3.0 & 1.9237 & 1.9237 & 1.92359 & 1.92368 \\
\hline & & 10.0 & 3.7207 & 3.7207 & 3.72159 & 3.72060 \\
\hline & & 100.0 & 12.2940 & & & 12.2940 \\
\hline & 1.5 & 0.72 & & 1.4944 & 1.49436 & 1.49437 \\
\hline & & 1.0 & & 2.0000 & 2.00000 & 2.00000 \\
\hline & & 10.0 & & 16.0842 & 16.09624 & 16.0842 \\
\hline \multirow[t]{3}{*}{1.0} & -1.5 & 1.0 & & 0.8095 & 0.80951 & 0.80951 \\
\hline & 0 & & & 1.3205 & 1.32052 & 1.32057 \\
\hline & 1.5 & & & 2.2224 & 2.22235 & 2.22236 \\
\hline
\end{tabular}


Table 3 Comparison $-\theta^{\prime}(0)$ for several values of Prandtl number in the absence of angle of inclination, Hartmann number, permeability parameter, Grashof number, modified Grashof number, thermal radiation, Schmidt number and mass slip.

\begin{tabular}{|c|c|c|c|c|c|c|c|c|c|c|c|c|c|c|c|}
\hline \multirow{2}{*}{ Pr } & \multirow{2}{*}{\multicolumn{2}{|c|}{$\begin{array}{l}\text { Bidin and } \\
\text { Nazar (2009) }\end{array}$}} & \multirow{2}{*}{$\begin{array}{l}\text { El-Aziz } \\
(2009)\end{array}$} & \multirow{2}{*}{$\begin{array}{l}\text { Ishak } \\
\text { (2011) }\end{array}$} & \multirow{2}{*}{\multicolumn{3}{|c|}{$\begin{array}{l}\text { Mukhopadhy } \\
\text { ay and Reddy } \\
\text { (2012) }\end{array}$}} & \multirow{2}{*}{ Present } & \multicolumn{7}{|c|}{ (2) } \\
\hline & & & & & & & & & \multicolumn{2}{|l|}{$\mathbf{A}^{*}$} & M & $\mathbf{R}$ & Pr & $\begin{array}{l}\text { Misra and } \\
\text { Sinha (2013) } \\
\end{array}$ & Present \\
\hline 1 & \multicolumn{2}{|l|}{0.9547} & 0.954785 & 0.9548 & \multicolumn{2}{|c|}{0.9547} & & 0.95479 & 3.0 & \multicolumn{2}{|r|}{0.5} & 1.0 & 21.0 & 0.46591 & 0.46591 \\
\hline 2 & \multirow{2}{*}{\multicolumn{2}{|c|}{1.4714}} & \multirow{2}{*}{0.46315} & \multirow{2}{*}{1.4715} & \multirow{2}{*}{\multicolumn{2}{|c|}{1.4714}} & & \multirow{2}{*}{1.47142} & 3.0 & \multicolumn{2}{|r|}{0.5} & 1.0 & 25.0 & 0.53355 & 0.55063 \\
\hline & & & & & & & & & 3.0 & & 0.5 & 2.0 & 21.0 & 0.32947 & 0.32979 \\
\hline 3 & \multicolumn{2}{|l|}{1.8691} & 1.869074 & 1.8691 & \multicolumn{2}{|c|}{1.8691} & & 1.86918 & 3.0 & & 1.0 & 1.0 & 21.0 & 0.42420 & 0.42420 \\
\hline 5 & 1.1599 & & 2.500132 & 2.5001 & & & & 2.50015 & 4.0 & & 0.5 & 1.0 & 21.0 & 0.39048 & 0.39046 \\
\hline 10 & & & 3.660372 & 3.6604 & & & & 3.66030 & & & & & & & \\
\hline $\begin{array}{l}\text { Tabl } \\
\text { and }\end{array}$ & $\begin{array}{l}\text { le } 5 \text { Valu } \\
\alpha=45^{\circ} .\end{array}$ & $f$ & $0),-\theta^{\prime}($ & and $-\phi$ & & & & of $\mathrm{Gr}$ & & $K$ & $\mathrm{Pr}$ & & & $A=0$ & $10 \mathrm{~S}$ \\
\hline $\mathbf{M}$ & $\mathbf{K}_{\mathbf{3}}$ & Gr & Gc & $\alpha$ & $\mathbf{R}$ & Pr & $\mathbf{A}^{*}$ & $\mathbf{B}^{*}$ & Ec & Sc & $\gamma$ & & (0) & $-\theta^{\prime}(\mathbf{0})$ & $-\phi^{\prime}(\mathbf{0})$ \\
\hline 1.0 & 0.4 & 2.0 & 2.0 & $\pi / 4$ & 0.5 & 21 & 0.5 & 0.5 & 0.5 & 0.6 & 0.5 & & 4622 & 0.835273 & 0.626557 \\
\hline 2.0 & 0.4 & 2.0 & 2.0 & $\pi / 4$ & 0.5 & 21 & 0.5 & 0.5 & 0.5 & 0.6 & 0.5 & & 9555 & 0.835703 & 0.620771 \\
\hline 1.0 & 0.6 & 2.0 & 2.0 & $\pi / 4$ & 0.5 & 21 & 0.5 & 0.5 & 0.5 & 0.6 & 0.5 & & 3346 & 0.834706 & 0.638644 \\
\hline 1.0 & 0.4 & 3.0 & 2.0 & $\pi / 4$ & 0.5 & 21 & 0.5 & 0.5 & 0.5 & 0.6 & 0.5 & & 9646 & 0.834410 & 0.628083 \\
\hline 1.0 & 0.4 & 2.0 & 3.0 & $\pi / 4$ & 0.5 & 21 & 0.5 & 0.5 & 0.5 & 0.6 & 0.5 & & 4370 & 0.834428 & 0.641994 \\
\hline 1.0 & 0.4 & 2.0 & 2.0 & $\pi / 2$ & 0.5 & 21 & 0.5 & 0.5 & 0.5 & 0.6 & 0.5 & & 4168 & 0.835303 & 0.584914 \\
\hline 1.0 & 0.4 & 2.0 & 2.0 & $\pi / 4$ & 1.5 & 21 & 0.5 & 0.5 & 0.5 & 0.6 & 0.5 & & 0756 & 0.787476 & 0.627688 \\
\hline 1.0 & 0.4 & 2.0 & 2.0 & $\pi / 4$ & 0.5 & 23 & 0.5 & 0.5 & 0.5 & 0.6 & 0.5 & & 5206 & 0.843220 & 0.626385 \\
\hline 1.0 & 0.4 & 2.0 & 2.0 & $\pi / 4$ & 0.5 & 21 & 1.0 & 0.5 & 0.5 & 0.6 & 0.5 & & 3486 & 0.826813 & 0.626992 \\
\hline 1.0 & 0.4 & 2.0 & 2.0 & $\pi / 4$ & 0.5 & 21 & 0.5 & 1.5 & 0.5 & 0.6 & 0.5 & & 4326 & 0.832285 & 0.626655 \\
\hline 1.0 & 0.4 & 2.0 & 2.0 & $\pi / 4$ & 0.5 & 21 & 0.5 & 0.5 & 1.0 & 0.6 & 0.5 & & 9335 & 0.787387 & 0.628364 \\
\hline 1.0 & 0.4 & 2.0 & 2.0 & $\pi / 4$ & 0.5 & 21 & 0.5 & 0.5 & 0.5 & 0.78 & 0.5 & & 3044 & 0.833755 & 0.691599 \\
\hline 1.0 & 0.4 & 1.0 & 2.0 & $\pi / 4$ & 0.5 & 21 & 0.5 & 0.5 & 0.5 & 0.6 & 1.0 & & 4156 & 0.833618 & 0.701039 \\
\hline
\end{tabular}

Table 6 Values of $f^{\prime \prime}(0),-\theta^{\prime}(0)$ and $-\phi^{\prime}(0)$ for various values of $\mathrm{Gr}, \mathrm{Gc}, \mathrm{S}, \mathrm{M}, K_{3}, \mathrm{R}, \mathrm{Pr}, \mathrm{A}^{*}, \mathrm{~B}^{*}, \mathrm{Sc}$ and $\gamma \quad$ with $\mathrm{A}=0.5, \mathrm{~S}_{\mathrm{f}}=1.5, \mathrm{~S}_{\mathrm{t}}=1.0, \mathrm{~S}_{\mathrm{c}}=$ 0.5 and $\alpha=45^{\circ}$.

\begin{tabular}{|c|c|c|c|c|c|c|c|c|c|c|c|c|c|c|}
\hline $\mathbf{M}$ & $\mathbf{K}_{3}$ & Gr & Gc & $\alpha$ & $\mathbf{R}$ & Pr & $\mathbf{A}^{*}$ & $\mathbf{B}^{*}$ & Ec & Sc & $\gamma$ & $f^{\prime \prime}(0)$ & $-\theta^{\prime}(\mathbf{0})$ & $-\phi^{\prime}(\mathbf{0})$ \\
\hline 1.0 & 0.4 & 2.0 & 2.0 & $\pi / 4$ & 0.5 & 21 & 0.5 & 0.5 & 0.5 & 0.6 & 0.5 & -0.423810 & 0.851735 & 0.677965 \\
\hline 2.0 & 0.4 & 2.0 & 2.0 & $\pi / 4$ & 0.5 & 21 & 0.5 & 0.5 & 0.5 & 0.6 & 0.5 & -0.436563 & 0.851604 & 0.673926 \\
\hline 1.0 & 0.6 & 2.0 & 2.0 & $\pi / 4$ & 0.5 & 21 & 0.5 & 0.5 & 0.5 & 0.6 & 0.5 & -0.397441 & 0.852300 & 0.686372 \\
\hline 1.0 & 0.4 & 3.0 & 2.0 & $\pi / 4$ & 0.5 & 21 & 0.5 & 0.5 & 0.5 & 0.6 & 0.5 & -0.419804 & 0.851240 & 0.678991 \\
\hline 1.0 & 0.4 & 2.0 & 3.0 & $\pi / 4$ & 0.5 & 21 & 0.5 & 0.5 & 0.5 & 0.6 & 0.5 & -0.388060 & 0.852315 & 0.689246 \\
\hline 1.0 & 0.4 & 2.0 & 2.0 & $\pi / 2$ & 0.5 & 21 & 0.5 & 0.5 & 0.5 & 0.6 & 0.5 & -0.509573 & 0.849030 & 0.649343 \\
\hline 1.0 & 0.4 & 2.0 & 2.0 & $\pi / 4$ & 1.5 & 21 & 0.5 & 0.5 & 0.5 & 0.6 & 0.5 & -0.420387 & 0.807054 & 0.678811 \\
\hline 1.0 & 0.4 & 2.0 & 2.0 & $\pi / 4$ & 0.5 & 23 & 0.5 & 0.5 & 0.5 & 0.6 & 0.5 & -0.424312 & 0.859021 & 0.677841 \\
\hline 1.0 & 0.4 & 2.0 & 2.0 & $\pi / 4$ & 0.5 & 21 & 1.0 & 0.5 & 0.5 & 0.6 & 0.5 & -0.423020 & 0.846069 & 0.678233 \\
\hline 1.0 & 0.4 & 2.0 & 2.0 & $\pi / 4$ & 0.5 & 21 & 0.5 & 1.5 & 0.5 & 0.6 & 0.5 & -0.423595 & 0.849618 & 0.678029 \\
\hline 1.0 & 0.4 & 2.0 & 2.0 & $\pi / 4$ & 0.5 & 21 & 0.5 & 0.5 & 1.0 & 0.6 & 0.5 & -0.419920 & 0.814690 & 0.679090 \\
\hline 1.0 & 0.4 & 2.0 & 2.0 & $\pi / 4$ & 0.5 & 21 & 0.5 & 0.5 & 0.5 & 0.78 & 0.5 & -0.431372 & 0.850344 & 0.745616 \\
\hline 1.0 & 0.4 & 1.0 & 2.0 & $\pi / 4$ & 0.5 & 21 & 0.5 & 0.5 & 0.5 & 0.6 & 1.0 & -0.431090 & 0.850320 & 0.741452 \\
\hline
\end{tabular}

The computed values of the concentration distribution for numerous values of Schmidt number, chemical reaction parameter, solutal slip and inclination are displayed in Figures 17-20. Figure 17 is a plot of concentration distribution for various values of Schmidt number. The Schmidt number is the ratio between a viscous diffusion rate and a molecular diffusion rate. We notice from this figure that the concentration distribution of the flow field reduces as the Schmidt number increases. This is due to the fact that heavier diffusing species have a greater retarding effect on the concentration distribution of the
Table 4 Comparison $-\theta^{\prime}(0)$ for several values of unsteadiness parameter, Hartmann number, Prandtl number and radiation number in the absence of angle of inclination, Grashof number, modified Grashof number, Schmidt number and mass slip. 
For the accuracy and validity, we compared the present numerical results corresponding to the skin-friction coefficient with that of Sharidan et al. (2006) and Chamka et al. (2010) (Table 1). Moreover, the present numerical values corresponding to the heat transfer coefficient compared with the previously published numerical results of Gurbka and Bobba (1985) Ishak et al. (2011) and Hayat et al. (2011) (Table 2), Bidin and Nazar, (2009) El-Aziz, (2009), Ishak (2011) and Mukhopadhyay and Reddy (2012) (Table 3), Misra and Sinha (2013) (Table 4). The Values of $f^{\prime \prime}(0),-\theta^{\prime}(0)$ and $-\phi^{\prime}(0)$ for different values of $M, K_{3}, G r, G c, \alpha, R, \operatorname{Pr}, A^{*}, B^{*}, E c, S c$ and $\gamma$ are shown in Table 5. It can be noted that the skin friction coefficient increased with increasing values of Grashof number, solutal Grashof number, permeability parameter, heat source, radiation and Eckert number, whereas the reverse trend is observed in the case of Hartmann number, Prandtl number, Schmidt number and chemical reaction for $\mathrm{A}=0$. Further, from Table 5, it is noticed that the Nusselt number increases with an increase in the Hartmann number, inclination and Prandtl number, where as it decreases with an increase in the radiation and Eckert number. From Table 6, it is noticed that the results are same as in the table.5, even after taking $A=0.5$. The Values of $f^{\prime \prime}(0)$, $-\theta^{\prime}(0)$ and $-\phi^{\prime}(0)$ for different values of $S_{f}, S_{t}$ and $S_{c}$ are shown in Table 7 for $A=0$. The skin-friction coefficient decreases with the thermal slip and concentration slip, while it increases with the velocity slip. The Nusselt number decreases with the thermal slip and concentration slip while increases with the velocity slip. It is seen that the value of Sherwood number decreases with an increase of thermal slip, velocity slip and concentration slip. From table.8, the same effects were seen as in the table. 7 for $A=0.5$.

Table 7 Values of $f^{\prime \prime}(0),-\theta^{\prime}(0)$ and $-\phi^{\prime}(0)$ for various values of $\mathrm{S}_{\mathrm{f}}$, $\mathrm{S}_{\mathrm{t}}, \mathrm{S}_{\mathrm{c}}$ with $\mathrm{A}=0.0, \mathrm{Gr}=2.0, \mathrm{Gc}=2.0, \mathrm{~S}=0.5, \mathrm{M}=1.0, K_{3}=0.4, \mathrm{R}=0.5$, $\operatorname{Pr}=21, \mathrm{~A}^{*}=0.5, \mathrm{~B}^{*}=0.5, \mathrm{Sc}=0.6, \gamma=0.5$ and $\alpha=45^{0}$.

\begin{tabular}{cccccc}
\hline$S_{f}$ & $S_{t}$ & $S_{c}$ & $f^{\prime \prime}(0)$ & $-\theta^{\prime}(0)$ & $-\phi^{\prime}(0)$ \\
\hline 0.5 & 0.5 & 0.5 & -0.824869 & 1.372580 & 0.649400 \\
1.0 & 0.5 & 0.5 & -0.540318 & 1.468520 & 0.634617 \\
0.5 & 1.0 & 0.5 & -0.829293 & 0.758747 & 0.649052 \\
0.5 & 0.5 & 1.0 & -0.863787 & 1.360400 & 0.486690 \\
\hline
\end{tabular}

Table 8 Values of $f^{\prime \prime}(0),-\theta^{\prime}(0)$ and $-\phi^{\prime}(0)$ for various values of $\mathrm{S}_{\mathrm{f}}$, $\mathrm{S}_{\mathrm{t}}, \mathrm{S}_{\mathrm{c}}$ with $\mathrm{A}=0.5, \mathrm{Gr}=2.0, \mathrm{Gc}=2.0, \mathrm{~S}=0.5, \mathrm{M}=1.0, K_{3}=0.4, \mathrm{R}=0.5$, $\mathrm{Pr}=21, \mathrm{~A}^{*}=0.5, \mathrm{~B}^{*}=0.5, \mathrm{Sc}=0.6, \gamma=0.5$ and $\alpha=45^{0}$.

\begin{tabular}{cccccc}
\hline$S_{f}$ & $S_{t}$ & $S_{c}$ & $\boldsymbol{f}^{\prime \prime}(\mathbf{0})$ & $-\theta^{\prime}(\mathbf{0})$ & $-\phi^{\prime}(\mathbf{0})$ \\
\hline 0.5 & 0.5 & 0.5 & -0.870470 & 1.413830 & 0.698093 \\
1.0 & 0.5 & 0.5 & -0.567534 & 1.506000 & 0.685004 \\
0.5 & 1.0 & 0.5 & -0.874783 & 0.779061 & 0.697800 \\
0.5 & 0.5 & 1.0 & -0.907093 & 1.402470 & 0.514883 \\
\hline
\end{tabular}

\section{CONCLUSION}

The steady two-dimensional heat and mass transfer on the MHD flow of blood over an inclined permeable stretching surface with nonuniform heat source/sink were numerically investigated. The governing boundary layer equations were reduced into a system of ordinary differential equations and then the equations were solved numerically. The main results of the present investigation are as follows:

$>$ By increasing Ec, the boundary layer as well as the temperature profiles on the stretching sheet are increased.

$>$ By increasing $\mathrm{R}$, the boundary layer of the fluid flow is increased as well as convective heat transfer rate on the stretching sheet is increased.

$>$ By increasing Pr, the boundary layer of the fluid flow and the heat transfer rate decreases.

\section{REFERENCES}

Darcy, H. 1937, "The Flow of Fluids through Porous Media", McGrawHill, NewYork, NY, USA.

Brinkman, H.C. 1949, “A Calculation of the Viscous Force Exerted by a Flowing Fluid on a Dense Swarm of Particles," Applied ScientificResearch, 1, 27-34.

https://doi.org/10.1007/BF02120313

Cokelet, G.R., Fung, Y.C., Perrone N. and Anliker, M., 1972, "Biomechanics-Its Foundations and Objectives," Prentice- Hall, Englewood Cliffs.

Chien, S., Usami S. and Skalak, R., 1984, "Blood Flow in Small Tubes," E. M. Renkins and C. C. Michel, Eds., American Physiological Society Handbook of Physiology, Section 2, The Cardiovascular System, 4, Bethesda MD, American Physiological Society, 217-249.

Bhatti, M.M. and Ali Abbas, M., 2016, "Simultaneous Effects of Slip and MHD on Peristaltic Blood Flow of Jeffrey Fluid Model through a Porous Medium," Alexandria Engineering Journal, 55, 1017-1023.

https://doi.org/10.1016/j.aej.2016.03.002

Ismail, Z., Abdullah, I., Mustapha N. and Amin, N., 2007, “A PowerLaw Model of Blood Flow Through a Tapered Overlapping Stenosed Artery," Applied Mathematics and Computation, 195, 669-680.

https://doi.org/10.1016/j.amc.2007.05.014

Sinha, A., Misra J.C. and Shit, G.C., 2016, "Effect of Heat Transfer on Unsteady MHD Flow of Blood in a Permeable Vessel in the Presence of Non-Uniform Heat Source," Alexandria Engineering Journal, 55, 2023-2033.

https://doi.org/10.1016/j.aej.2016.07.010

Barozzi, G.S. and Dumas, A.J., 1991, "Convective Heat Transfer Coefficients in the Circulation," J. Biomech. Eng. 113, 308-310.

https://doi.org/10.1115/1.2894889

Bala Anki Reddy, P., Venkateswara raju K. and Suneetha, S., 2016, "Effects of Variable Viscosity and Thermal Diffusivity on MHD Free Convection Flow along a Moving Vertical Plate Embedding in a Porous Medium with Heat Generation," Global Journal of Pure and Applied Mathematics, 12 (3), 558-564.

Bhatti, M.M., Ali Abbas, M. and Rashidi, M.M., 2018, “A Robust Numerical Method for Solving Stagnation Point Flow over a Permeable Shrinking Sheet Under the Influence of MHD," Applied Mathematics and Computation, 316, 381-389.

https://doi.org/10.1016/j.amc.2017.08.032

Mahabaleshwar, U.S., Sarris, I.E., Hill, A.A., Giulio Lorenzini and Ioan Pop, 2017, "An MHD Couple Stress Fluid due to a Perforated Sheet Undergoing Linear Stretching with Heat Transfer," International Journal of Heat and Mass Transfer, 105, 157-167. https://doi.org/10.1016/j.ijheatmasstransfer.2016.09.040

Bhatti, M.M., Tehseen Abbas, and Rashidi, M.M., 2017, "Entropy Generation as a Practical Tool of Optimisation for Non-Newtonian Nanofluid Flow Through a Permeable Stretching Surface using SLM," Journal of Computational Design and Engineering, 4(1), 21-28. https://doi.org/10.1016/j.jcde.2016.08.004

Mabood, F., Ibrahim, S.M., Rashidi, M.M., Shadloo, M.S. and Giulio Lorenzini, 2016, "Non-Uniform Heat Source/Sink and Soret Effects on MHD Non-Darcian Convective Flow Past a Stretching Sheet in a Micropolar Fluid with Radiation," International Journal of Heat and Mass Transfer, 93, 674-682.

https://doi.org/10.1016/j.ijheatmasstransfer.2015.10.014

Jia Qing, Bhatti, M.M., Ali Abbas, M., Rashidi, M.M., and Mohamed El-Sayed Ali, 2016, "Entropy Generation on MHD Casson Nanofluid Flow over a Porous Stretching/Shrinking Surface," Entropy, 18(4), 123. 


\section{https://doi.org/10.3390/e18040123}

Bhatti, M.M., Tehseen Abbas, Rashidi, M.M., and Mohamed El-Sayed Ali, 2016, "Numerical Simulation of Entropy Generation with Thermal Radiation on MHD Carreau Nanofluid towards a Shrinking Sheet," Entropy, 18(6), 200.

https://doi.org/10.3390/e18060200

Abdul Hakeem, A.K., Renuka, P., Vishnu Ganesh, N., Kalaivanan R. and Ganga, B., 2016, "Influence of Inclined Lorentz Forces on Boundary Layer Flow of Casson Fluid over an Impermeable Stretching Sheet with Heat Transfer," Journal of Magnetism and Magnetic Materials, 401, 354-361.

https://doi.org/10.1016/j.jmmm.2015.10.026

Nasir Ali, Sami Ullah Khan, Muhammad Sajid and Zaheer Abbas, 2016, "MHD Flow and Heat Transfer of Couple Stress Fluid over an Oscillatory Stretching Sheet with Heat Source/Sink in Porous Medium," Alexandria Engineering Journal, 55, 915-924.

https://doi.org/10.1016/j.aej.2016.02.018

Gurbka, L.J. and Bobba, K.M., 1985, "Heat Transfer Characteristics of a Continuous Stretching Surface with Variable Temperature," ASME J Heat Transfer, 197, 248-250.

Sharidan, S., Mahmood T. and Pop, I., 2006, "Similarity Solutions for the Unsteady Boundary Layer Flow and Heat Transfer due to a Stretching Sheet," Int J ApplMechEng. 11, 647-654.

Bhatti, M. M. and Rashidi, M. M. 2016, "Entropy Generation with Nonlinear Thermal Radiation in MHD Boundary Layer Flow over a Permeable Shrinking/Stretching Sheet: Numerical Solution," Journal of Nanofluids, 5(4), 543-548.

https://doi.org/10.1166/jon.2016.1248

Chamka, A.J., Aly A.M., and Mansour, M.A., 2010, "Similarity Solution for Unsteady Heat and Mass Transfer from a Stretching Surface Embedded in a Porous Medium with Suction/Injection and Chemical Reaction Effects," Chem. Eng. Comm. 197, 846-858.

http://dx.doi.org/10.1080/00986440903359087

Szasz, A., 2007, "Hyperthermia, a Modality in the Wings," J Cancer Res Ther. 3, 56-66.

http://dx.doi.org/10.4103/0973-1482.31976

Misra, J.C., Sinha A. and Shit, G.C., 2010, "Flow of a Biomagnetic Viscoelastic Fluid: Application to Estimation of Blood Flow in Arteries during Electromagnetic Hyperthermia, a Therapeutic Procedure for Cancer Treatment," Appl. Math. Mech. -Engl. Ed. 31, 1405-1420. https://doi.org/10.1007/s10483-010-1371-6

Inoue, S. and Kobaya, M., 1989, "Biological Activities Caused by Far Infrared Radiation,” Int. J. Biometeorol. 33, 145-150.

https://doi.org/10.1007/BF01084598

Nishimoto, C., Ishiura, Y., Kuniasu K. and Koga, T., 2006 "Effects of Ultrasonic Radiation on Cutaneous Blood Flow in the Paw of Decerebrated Rats," Kawasaki J. Med Welfare. 12, 13-18.

Bidin, B. and Nazar, R., 2009, "Numerical Solution of the Boundary Layer Flow over an Exponentially Stretching Sheet with Thermal Radiation," European Journal of Scientific Research, 33, 710-717. http://hdl.handle.net/123456789/9055

Irfan Rashid, Rizwan Ui Haq and Qasem M. Al-Mallal, 2017, “Aligned Magnetic Field Effects on Water Based Metallic Nanoparticles over a Stretching Sheet with PST and Thermal Radiation Effects," Physica E: Low-dimensional Systems and Nanostructures, 89, 33-42. https://doi.org/10.1016/j.physe.2017.01.029

Ishak, A. 2011, "MHD Boundary Layer Flow due to an Exponentially Stretching Sheet with Radiation Effect," Sains Malays. 40, 391-395.
Misra, J.C. and Sinha, A., 2013, "Effect of Thermal Radiation on MHD Flow of Blood and Heat Transfer in a Permeable Capillary in Stretching Motion," Heat Mass Transfer, 49, 617-628.

https://doi.org/10.1007/s00231-012-1107-6

Misra, J.C., Patra M.K. and Misra, S.C., 1993, "A Non-Newtonian Fluid Model for Blood Flow Through Arteries under the Stenotic Conditions," J. Biomech. 26, 1129-1141. https://doi.org/10.1016/S0021-9290(05)80011-9

Ebart, W.A. and Sparrow, E.M., 1965, "Slip Flow in Rectangular and Annular Ducts," J. Basics Eng. 87, 1018-1024. https://doi.org/10.1115/1.3650793

Brunn, P., 1975, “The Velocity Slip of Polar Fluids," Rheol. Acta. 14, 1039-1054.

https://doi.org/10.1007/BF01515899

Nubar, Y., 1971, "Blood Flow, Slip and Viscometry," J. Biophys. 11, 252-264.

https://doi.org/10.1016/S0006-3495(71)86212-4

Misra, J.C. and Kar, B.M., 1989, "Momentum Integral Method for Studying Flow Characteristics of Blood Through a Stenosed Vessel," Biorheology, 26, 23-25.

Bala Anki Reddy, P. and Raja Das, 2016, "Estimation of MHD Boundary Layer Slip Flow over a Permeable Stretching Cylinder in the Presence ff Chemical Reaction Through Numerical and Artificial Neural Network Modelling," Engineering Science and Technology, an International Journal, 19, 1108-1116.

https://doi.org/10.1016/j.jestch.2015.12.013

Hayat, T., Qasim M. and Mesloub, S., 2011, "MHD Flow and Heat Transfer over Permeable Stretching Sheet with Slip Conditions," Int $J$ Numer Meth Fluids, 66, 963-975. https://doi.org/10.1002/fld.2294

Mukhopadhyay, S., Rama Subba Reddy Gorla, 2012, "Effects of Partial Slip on Boundary Layer Flow Past a Permeable Exponential Stretching Sheet in Presence of Thermal Radiation," Heat Mass Transfer. 48 , 1773-1781.

https://doi.org/10.1007/s00231-012-1024-8

Bala Anki Reddy, P. and Suneetha, S., 2017, "Effects of HomogeneousHeterogeneous Chemical Reaction And Slip Velocity on MHD Stagnation Flow of a Micropolar Fluid over a Permeable Stretching/Shrinking Surface Embedded in a Porous Medium," FHMT, 8 (24) 1-11. http://dx.doi.org/10.5098/hmt.8.24

Gebhart, B., 1962, "Effects of Viscous Dissipation in Natural Convection," J. Fluid Mechanics, 14, 225-232.

https://doi.org/10.1017/S0022112062001196

Brinkman, H.C., 1951, "Heat Effects in Capillary Flow I," Appl. Sci. Res A. 2, 120-124.

https://doi.org/10.1007/BF00411976

Chand, G. and Jat, R.N., 2014, "Viscous Dissipation and Radiation Effects on MHD Flow and Heat Transfer over an Unsteady Stretching Surface in a Porous Medium,” Therm. Energy Power Eng. 3, 266-272.

El-Aziz, M.A. 2009, "Viscous Dissipation Effect on Mixed Convection Flow of a Micropolar Fluid over an Exponentially Stretching Sheet," Can J. Phys. 87, 359-368. https://doi.org/10.1139/P09-047

Srinivas, S., Reddy P.B.A. and Prasad, B.S.R.V., 2014, "Effects of Chemical Reaction and Thermal Radiation on MHD Flow over an Inclined Permeable Stretching Surface with Non-Uniform Heat Source/Sink: An Application to the Dynamics of Blood Flow," J. Mech. Med. Biol. 14, 1450067-1-24.

https://doi.org/10.1142/S0219519414500675 